\title{
Potential of Raman Spectroscopy For the Analysis of Plasma/ serum in the Liquid State: Recent Advances
}

Drishya Rajan Parachalil

Technological University Dublin, drishyarajan.parachalil@mytudublin.ie

Jennifer McIntyre

Technological University Dublin, jennifer.mcintyre@tudublin.ie

Hugh J. Byrne

Technological University Dublin, hugh.byrne@tudublin.ie

Follow this and additional works at: https://arrow.tudublin.ie/nanolart

Part of the Pharmacology, Toxicology and Environmental Health Commons

\section{Recommended Citation}

Parachalil, R., McIntyre, J., Byrne, H.J. (2019). Potential of Raman spectroscopy for the analysis of plasma/serum in the liquid state: Recent advances. Analytical and Bioanalytical Chemistry.

This Article is brought to you for free and open access by the NanoLab at ARROW@TU Dublin. It has been accepted for inclusion in Articles by an authorized administrator of ARROW@TU Dublin. For more information, please contact arrow.admin@tudublin.ie, aisling.coyne@tudublin.ie,gerard.connolly@tudublin.ie.

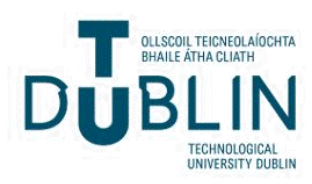




\title{
Potential of Raman spectroscopy for the analysis of plasma/serum in the liquid state: Recent advances
}

\author{
Drishya Rajan Parachalil ${ }^{\mathrm{a}, \mathrm{b} *}$, Jennifer McIntyre ${ }^{\mathrm{a}}$, and Hugh J. Byrne ${ }^{\mathrm{a}}$ \\ ${ }^{a}$ FOCAS Research Institute, Technological University of Dublin, Kevin Street, Dublin 8, \\ Ireland \\ ${ }^{b}$ School of Physics and Optometric \& Clinical Sciences, Technological University of Dublin, \\ Kevin Street, Dublin 8, Ireland \\ *Corresponding Author: drishyarajan.parachalil@mydit.ie
}

\begin{abstract}
There is compelling evidence in the literature to support the application of Raman spectroscopy for analysis of bodily fluids in their native liquid state. Naturally, the strategies described in the literature for Raman spectroscopic analysis of liquid samples have advantages and disadvantages. Herein, recent advances in the analysis of plasma/serum in the liquid state are reviewed. The potential advantages of Raman analysis in the liquid form over the commonly employed infrared absorption analysis in the dried droplet form are initially highlighted. Improvements in measurement protocols based on inverted microscopic geometries, clinically adaptable substrates, data preprocessing and analysis, and applications for routine monitoring of patient health as well as therapeutic administration are reviewed. These advances suggest that clinical translation of Raman spectroscopy for rapid biochemical analysis can be a reality. In the future, this method will prove to be highly beneficial to clinicians for rapid screening and monitoring of analytes and drugs in the biological fluids, and to the patients themselves, enabling early treatment, before the disease becomes symptomatic, allowing early recovery.
\end{abstract}

Keywords: Raman spectroscopy, Extended Multiplicative Signal Correction, Therapeutic drug monitoring, Disease diagnosis, Serum, Plasma, Partial Least Squares Regression 


\section{Introduction}

Vibrational spectroscopic techniques, both Raman and Infrared (IR) absorption, have been extensively explored over the last two decades for obtaining the biochemical composition of bodily fluids in the field of biomedical analysis [1-10]. The sensitivity to detect subtle changes in the biochemical composition and ability to detect the presence of specific biomarkers or drugs makes vibrational spectroscopy an ideal tool for the early diagnosis of various pathologies [11-14] and therapeutic drug monitoring [15-17]. Both techniques are truly label free, rapid, cost-effective, easy to operate, non-destructive and provide the unique molecular fingerprint of the sample with minimal sample preparation steps. Such techniques are particularly attractive for routine analysis of biofluids, as they are easy to apply, require minimal sample preparation and are readily adaptable to analysis of various bodily fluids [15], potentially reducing clinical analysis time, and alleviating patient angst (figure 1).

Over the past decades, there have been numerous studies of analytes in biofluids using vibrational spectroscopy, and, in recent years, attenuated total reflection (Fourier Transform) IR (ATR-FTIR) has become popular for rapid screening of biofluids, particularly blood plasma and serum [13]. Notably, however, ATR-FTIR is predominantly conducted on dried droplets of bodily fluids, adding to the complexity of the measurement and the clinical workflow [18, 19]. In comparison, the prospect of using Raman spectroscopy for the label-free extraction of biochemical information from biological fluids is attractive from various perspectives; liquid sample analysis, no requirement for additional reagents, ease of use, speed, cost-effectiveness and low sample volume requirement. The application of Raman spectroscopy to biomolecules and even tissues was first demonstrated as early as the 1960s, and by the mid 1970s biomedical applications were explored [20-22]. Whole cell and tissue studies have been carried out on a range of pathologies [23-25] and in vivo studies [26, 27] have demonstrated the prospective for diagnostic applications. Raman microspectroscopy potentially lends itself naturally to the 
analysis of liquid biofluids and such applications have attracted considerable attention in recent years. There have been, however, multiple strategies that are used to perform such real-time analysis and these options must be carefully considered to achieve optimum Raman spectra from liquid samples [28, 29]. Several studies have reported the proof-of-concept of liquid sample analysis using Raman spectroscopy [30-37]. However, no systematic validation and testing of protocols has yet been carried out to consider this technique for real-time clinical applications. This review will summarise the recent advances in the standardisation of measurement protocol for biological fluid analysis in the liquid state using Raman spectroscopy, in terms of the optimal wavelength and substrate, serum fractionation methods, data collection, pre-processing and post processing steps to obtain results with higher accuracy and sensitivity. Applications for both analysis of imbalances of high and low molecular weight serum constituent components of pathological and clinical significance, as well as therapeutic drug monitoring will be considered. Note, that the studies considered do not require signal enhancement techniques such as surface enhanced Raman spectroscopy, and therefore such techniques are not considered within the scope of the review. However, as they has been extensively explored in recent times, a brief comparison of the techniques to infrared absorption based techniques is provided. 


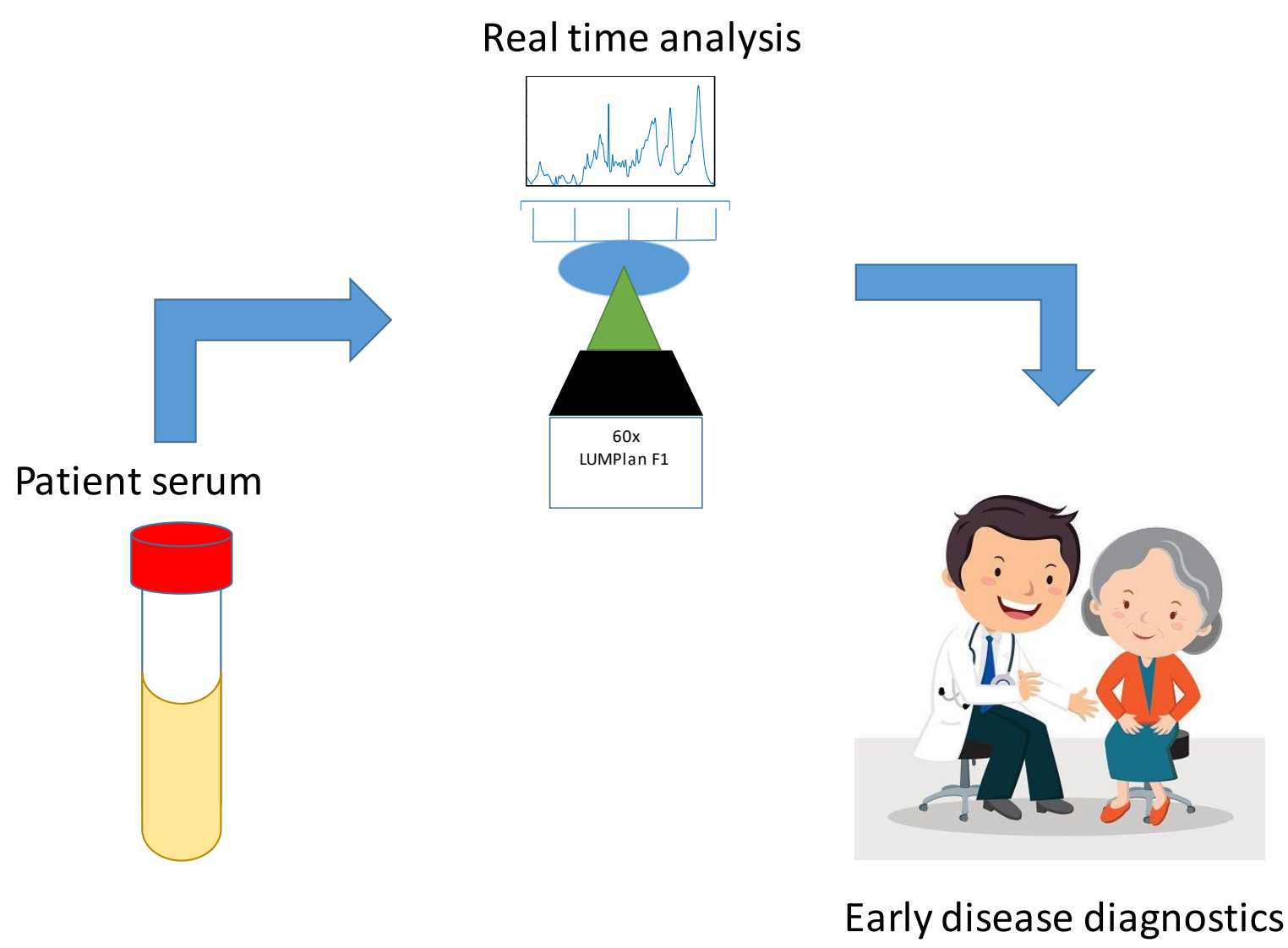

Figure 1. Early disease diagnosis, prognosis and treatment is possible with real-time analysis of patient serum using the inverted Raman spectral analysis.

\section{Raman vs Infrared absorption spectroscopy}

Although Raman and IR spectroscopy are considered complementary techniques, the fundamental physical phenomena governing them are very different, and thus result in distinct technical challenges to their clinical implementation $[6,38]$. As IR spectroscopy is based on absorption due to electric dipole transitions associated with molecular vibrations, water cannot be used as a solvent, due to its intense absorption in the IR region due to the highly polar $\mathrm{OH}$ groups $[39,40]$. IR analysis of bodily fluids has therefore been predominantly performed on air-dried samples, which leads to chemical and physical inhomogeneity due to the so - called "coffee ring" effect and thereby inconsistencies in the results obtained [18, 19, 39]. Raman spectroscopy is an inelastic scattering technique based on the Raman effect, i.e., the coupling 
of the oscillating electronic polarisabilities of the molecular bond with the source electromagnetic field $[41,42]$. The distinct advantage of this technique is that it is compatible with water-rich samples such as serum/plasma, as water molecules have a relatively low scattering cross section and do not mask the scattering from the solutes in the aqueous solutions [43-45]. Zhao et al., developed a fast and reliable approach to identify and quantify liquid injectables in the liquid state for spurious/falsely-labelled/falsified/counterfeit medical products (SFFCs) using Raman spectrophotometer of 785nm excitation source [46]. Principle Component Analysis (PCA) combined with Classical Least Squares (CLS) chemometric methods were used to overcome the problems of the interference signals of glass containers and solutions, and weak signals from active pharmaceutical ingredients were finally extracted. Water was used as an internal standard for normalisation and CLS quantitation models were established. When Raman predicted values were compared with HPLC reference results, the relative error of eight doxofylline liquid injectable samples were within 5\% and three lowconcentration Levofloxacin in Levofloxacin Lactate and Sodium Chloride Injection samples were within $10 \%$, demonstrating this approach to be a reliable and rapid screening method to detect SFFCs in liquid dosage forms. In order to extend this Raman spectroscopic set up for the study of biological fluids, further studies should be conducted on biological fluids to extract clinically relevant information.

Multianalyte, dried serum analysis has previously been reported using mid-infrared spectroscopy, for the simultaneous quantitation of eight serum analytes: total protein content, albumin, triglycerides, cholesterol, glucose, urea, creatinine and uric acid [47] and for simultaneous quantification of glucose and urea analytes along with malaria parasitemia quantification using ATR-FTIR [11]. As a direct comparison of the techniques of mid-IR and Raman spectroscopy, together with multivariate data analysis, for the quantitative analysis of serum, Rohleder et al. analysed the serum of 247 blood donors [36]. The IR analysis was 
undertaken on dried droplets, whereas the Raman analysis was of the liquid serum and/or serum filtrates. Under their investigation for the quantification of glucose, urea, uric acid, LDL cholesterol, HDL cholesterol, total protein, cholesterol and triglycerides, Raman and midinfrared spectroscopy delivered similar accuracies for the prediction of physiologically relevant analyte levels [36]. More recently, Parachalil et al., undertook a similar comparison of Raman compared to ATR-FTIR, using identical sample preparation and analysis protocols, to quantitatively monitor diagnostically relevant changes of glucose [44], indicating that Raman spectroscopy in the liquid state can perform at least as well as ATR-FTIR, without the need for the drying step.

Notably, whereas many of the previous studies of liquid serum samples employed an upright microscopic geometry, that of Parachalil et al., employed an inverted geometry, as previously demonstrated by Bonnier et al. [62]. Improved analysis of serum using Raman spectroscopy was reported when the sample was analysed in the inverted geometry using a water immersion objective with a $785 \mathrm{~nm}$ laser and $\mathrm{CaF}_{2}$ substrate. A drop of water is used to minimise the differences in the refractive indices between sample, objective and the substrate, and thus improve the optical coupling. However, the water drop does not contribute to the data collected, as it is outside the focus of the beam. As a much better cost-effective, clinically adaptable option, Parachalil et al. introduced a commercial, cover slip (of 0.16-0.19 mm thickness) bottomed vesicle (Lab-tek plate) as the substrate. The use of glass precludes the use of a $785 \mathrm{~nm}$ source $[48,49]$, and thus a $532 \mathrm{~nm}$ laser was chosen as the source, which provides a strong Raman signal of water with minimal background interference (Figure 2). This set-up also has the added advantage of providing high quality, consistent Raman spectra from a sample volumes as low as $1 \mu \mathrm{L}$. Medipally et al. also reported the benefits of using inverted Raman geometry to analyse plasma samples of small volume $(20 \mu \mathrm{L})$ from prostate cancer patients 
[50]. Note, enhanced methods such as Surface Enhanced Raman Spectroscopy (SERS) are not considered in this review.

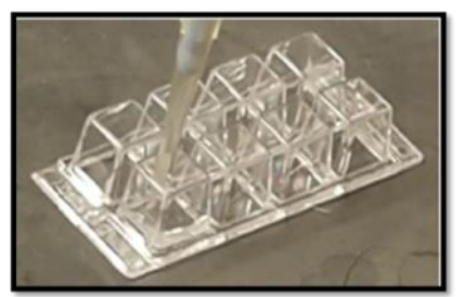

Lab-Tek plate
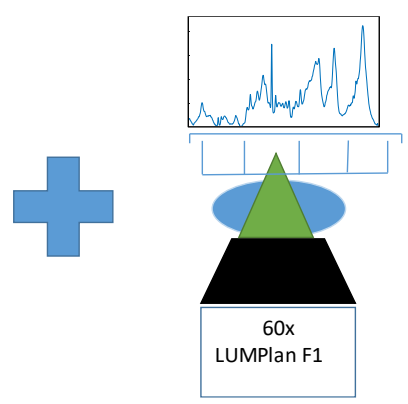

The volume of the sample measured can be as low as $1 \mu \mathrm{L}$. The spectral features are found to be stable at the highest and the lowest volume

Figure 2. Thin glass bottomed Lab-Tek plate combined with inverted Raman analysis can collect spectral data from very low amount of samples $(1 \mu \mathrm{L})$ making it an ideal tool for clinical laboratory analysis. Spectra can be recorded in less than 1 minute.

\section{Measurement of Plasma vs Serum}

Human blood plasma or serum are the most commonly studied bodily fluids for disease diagnosis, biomarker discovery and therapeutic drug monitoring [51-57]. While plasma and serum are both cell-free fluids obtained from blood samples by centrifugation, they differ on the basis of whether clotting has been allowed or not. One question which inevitably arises in performing biochemical estimation of blood, therefore, is what is the right choice of medium to be used, plasma or serum? Plasma is commonly obtained as the supernatant layer after refrigerated centrifugation of blood collected with anticoagulants (such as potassiumEthylenediaminetetraacetic acid, sodium-citrated and lithium-heparin) for 10 minutes at 2,000 $\mathrm{x} g$ to concentrate unwanted cells and platelets [58]. For serum preparation, whole blood is allowed to clot at room temperature for about 15-30 minutes, whereupon the clot is removed by refrigerated centrifugation at $1,000-2,000 \times \mathrm{g}$ for 10 minutes, often separated by a gel component to avoid contamination [58]. It is important to immediately transfer the supernatant (plasma or serum) into a clean polypropylene tube and maintain samples at $2-8^{\circ} \mathrm{C}$ while handling. If the samples are not analysed immediately, they should be stored at $-20^{\circ} \mathrm{C}$ or 
preferably lower [59]. The time delay between centrifugation and separation of the globular fraction and the improper storage conditions could negatively impact on the protein profile obtained [59]. Therefore, standardisation of sample collection, processing and storage protocols is crucial to ensure reproducibility and consistency in the results obtained. It is also recommended to avoid freeze-thaw cycles, because this may have detrimental effects on many serum components [60].

Blood serum and plasma are predominantly composed of water ( 90\%), minerals, organic substances and gas (oxygen, carbon dioxide) [60]. Proteins are the predominant molecular components of blood plasma, the remaining constituents being carbohydrates, lipids and amino acids. Serum albumin, globulins, fibrinogen and a handful of other abundant proteins account for $99 \%$ of total plasma/serum proteins, while the remaining $1 \%$ is composed of low abundance circulatory proteins [54]. Additionally, plasma or serum contain more than 114,000 known metabolites at varying concentration level ( $<1 \mathrm{nmol} / \mathrm{L}$ to $\mathrm{mmol} / \mathrm{L})[60]$ '

Since most of the clinical analytical instruments are accurate for both serum and plasma, these two terms are used erroneously interchangeably in most clinical tests [7]. Notably, many studies that have been reported to be carried out in serum were in fact carried out in plasma [61-66].

Medipally et al. investigated the effect of different instrumental and sample preparation parameters to identify a combination that would reduce the overall acquisition time for recording spectra from blood plasma with minimal of sample preparation steps [50]. Out of the four different laser lines $(785 \mathrm{~nm}, 660 \mathrm{~nm}, 532 \mathrm{~nm}$ and $473 \mathrm{~nm}$ ) tested, only the $785 \mathrm{~nm}$ laser line gave a reliable biochemical signature of liquid plasma samples. Fluorescence was observed when the $660 \mathrm{~nm}$ laser line was used and a resonance Raman effect due to the presence of $\beta$ carotene was observed when 532 and $473 \mathrm{~nm}$ laser lines were used. Plasma samples from 10 
prostate cancer patients and 10 healthy volunteers were used in this study. A 96 well plate (cover glass bottomed) was used to hold samples of $20 \mu \mathrm{L}$ and the Raman spectra were recorded in the inverted geometry. Spectral preprocessing steps and principal component analysis - linear discriminant analysis (PCA-LDA) was performed in the R environment. The classification resulted in a sensitivity and specificity of $96.5 \%$ and $95 \%$ respectively. Although a cost effective approach to perform rapid analysis of liquid plasma is demonstrated in this study, no attempts have been made to reduce the effect of spectral interferents while using the $532 \mathrm{~nm}$ laserline.

In validating the protocols for analysis of bodily fluids using inverted Raman microscopic analysis using 532nm, Parachalil et al. utilised a simulated blood plasma mixture of albumin, fibrinogen, cytochrome C, and vitamin B12 [44]. The findings from this study with simulated plasma protein mixture show that the poorly soluble fibrinogen component obscured the systematic variations of the protein concentrations due to high degree of scattering. Mild sonication of the aqueous solution helped to improve the solubility of fibrinogen and significantly improved the Raman spectral intensity by minimising scattering effects. Since centrifugal filtration failed to separate fibrinogen from rest of the proteins, ion exchange chromatography had to be applied to separate the fibrinogen by altering its net surface charge. Although ion exchange chromatography is a quick method to separate proteins, this method has to be tailored for a specific protein depending on its charge and cannot be used as a 'onefor-all' separation kit for all the proteins. In terms of the applications of Raman Spectroscopy for analysis of blood content, it is therefore recommended that fibrinogen content should be extracted from plasma, and mildly sonicated for quantitation, whereas blood serum can be readily further analysed for High Molecular Weight Fraction (HMWF) and Low Molecular Weight Fraction (LMWF) quantification.

\section{Serum Fractionation}


As long ago as 1999, Berger et al. used near IR light at 830nm to perform Raman microscopic analysis of liquid whole human blood and serum samples to quantify the content of six analytes, namely glucose, cholesterol, triglyceride, urea, total protein and albumin [28]. The total acquisition time per sample was 5 min and the samples were continuously stirred in a quartz cuvette to minimise heating artefacts from high intensity laser. However, no attempts were made to fractionate the serum to deplete the HMWF analytes.

Centrifugal filtration devices have been utilised to improve the sensitivity of quantitative analysis by both Raman and IR spectroscopy, by separating the molecules according to their molecular weight [68]. The proteins that are highly abundant in serum dominate the spectral profile, and by the removal of these proteins (albumin and globulins,) the ability to monitor changes in the lower molecular weight fraction (LMWF) is enhanced. Pre-rinsing of the filter devices with $0.1 \mathrm{M} \mathrm{NaOH}$ prior to plasma analysis is essential to avoid glycerine interference in the analysis [67]. The optimised washing and rinsing procedure includes spinning $0.5 \mathrm{~mL}$ $0.1 \mathrm{M} \mathrm{NaOH}$ at $14000 \times \mathrm{g}$ for 30 minutes, followed by three rinses with distilled water by spinning $0.5 \mathrm{~mL}$ distilled water for 30 minutes at $14000 \times \mathrm{g}$. Every 30 minute wash and rinse must be followed by spinning the device in the inverted position at $1000 \times \mathrm{g}$ for 2 minutes, to remove the residual solution contained in the filter. After washing, $0.5 \mathrm{~mL}$ sample is transferred to the filter and centrifuged at $14000 \times \mathrm{g}$ for 30 minutes. The solution that flows out from the filter is the filtrate, which contains mostly water and molecules smaller than the pore size of the chosen filter. The remainder of the sample, known as the concentrate, is collected by placing the filter device upside down and spinning for $1000 \times \mathrm{g}$ for 2 minutes. The resultant concentrate, $\sim 50 \mu \mathrm{L}$, contains molecules with molecular weight larger than chosen pore size, and is concentrated by a factor of $\sim 10$. This indicates the potential for the prediction of other biomolecules that exist within the LMWF with this method, and with further research, such 
techniques could be translated into the clinical environment as a rapid tool for screening and monitoring.

In the study conducted using 247 blood donors by Rohleder et al. [37], a key was that the prediction accuracy of glucose and urea were improved by up to a factor of 2 by depletion of the HMWF using centrifugal filtration techniques. The processing protocol has been extensively explored for both ATR-FTIR and Raman analysis [39, 68] whereby the HMWF can be isolated in the unfiltered concentrate, while the LMWF filtrate can be further fractionated and/or concentrated. Notably, Bonnier et al. have highlighted the importance of appropriate rinsing of the filters to avoid contamination of the filtrate [67]. In the study of Rohleder et al. [37], Raman spectroscopy was used for quantitative analysis of serum and serum ultrafiltrate with an accuracy, within the range of clinical interest [37], by using 785nm laser as the excitation wavelength and a quartz cuvette to hold the sample. In this measurement setup, a minimum of $200 \mu \mathrm{L}$ sample was required. $10 \mathrm{kDa}$ centrifugal filters were used to deplete the HMWF from the serum and the spectra of glucose, urea and uric acid were recorded from the serum as well as the ultrafiltrate.

Parachalil et al. further demonstrated the suitability of Raman spectroscopy as a bioanalytical tool, when coupled with ultra-filtration and multivariate analysis, to detect imbalances in both HMWF (total protein content, $\gamma$ globulins and albumin) and LMWF (urea and glucose) of the same samples of human patient serum, in the native liquid form [69]. Using a validated Partial Least Squares Regression (PLSR) method, the $\gamma$ globulin and total protein analysis models, based on unfiltered patient serum, produced $\mathrm{R}^{2}$ values of 0.88 and 0.82 , and Root Mean Square Error of Crossvalidation (RMSECV) of $126 \mathrm{mg} / \mathrm{dL}$ and $115 \mathrm{mg} / \mathrm{dL}$, respectively. Post fractionation of the patient serum samples by ultra-filtration using $100 \mathrm{kDa}$ and $50 \mathrm{kDa}$ filters, a similar analysis produced an $\mathrm{R}^{2}$ value of 0.91 and RMSECV of $90 \mathrm{mg} / \mathrm{dL}$ for albumin, which is comparable to the values previously reported for a model of aqueous solutions of albumin 
over a similar concentration range. In the case of urea, $\mathrm{R}^{2}$ and RMSECV values of 0.90 and $70.40 \mathrm{mg} / \mathrm{dL}$ for the range of aqueous solutions of varying concentrations were achieved, and 0.92 and $1.73 \mathrm{mg} / \mathrm{dL}$, for the low molecular weight $(<10 \mathrm{kDa})$ filtrate of patient samples, when the full spectral range of $400-1800 \mathrm{~cm}^{-1}$ was employed. Reducing the spectral range of the analysis to $800 \mathrm{~cm}^{-1}$ to $1030 \mathrm{~cm}^{-1}$ considerably improved the prediction accuracy and sensitivity, resulting in an $\mathrm{R}^{2}$ value of 0.97 and RMSECV of $1.14 \mathrm{mg} / \mathrm{dL}$. In the case of glucose, a reduced spectral range from $1030 \mathrm{~cm}^{-1}$ to $1400 \mathrm{~cm}^{-1}$ was chosen to avoid interference from urea, resulting in an $\mathrm{R}^{2}$ value of 0.84 and RMSECV value of $1.84 \mathrm{mg} / \mathrm{dL}$ in the filtrate from the same patient samples. Although both the proof-of-concept studies have been carried out on rather small populations ( 25 patient samples), they demonstrate that the method has potential for clinical implementation for early disease diagnostics from bodily fluids. In this work, ultrafiltration in conjunction with chemometric methods were used to overcome three problems: first, eliminating the interference from water and $\beta$-carotene; second, extracting the Raman signals from LMWF analytes; and third, solving the problems associated with multiple analyte variations in the serum. The sample preprocessing enables a fractionation and concentration of the different molecular weight fractions of the serum, enabling their analysis and quantification without the need for additional enhancement techniques. It has been demonstrated that, using Ag or Au colloids, intense and repeatable spectra are only obtained if the high molecular weight protein fraction is filtered out from the serum [70]. Enhanced signals of the low molecular weight fraction can then be obtained, although the process of addition of colloids would add to the workflow in terms of time and cost. 


\section{Data preprocessing}

Data preprocessing, such as spikes removal, baseline correction, smoothing etc., aims to remove any perturbations to the spectra due to any distortions to the spectra which might arise during the measurement process (scattering, electronic noise). This pretreatment of data is critical to accessing the desired information without losing crucial information. The fundamental concepts and basic theory of most used chemometric tools in the pharmaceutical industry for pre-processing, processing and post-processing of the generated data have been detailed in the review article by Sacre et. al [71]. The majority of the commercial software, e.g. Labspec, includes real-time spikes correction, enabling visual inspection of the spectra, and/or manual spike removal when very few spikes are present. Some algorithms have been developed to perform automated spike removal in the case of a large dataset, for which manual correction is not possible [72-76]. The most commonly used smoothing algorithm for de-noising the spectra without losing much information is that of Savitzky-Golay [77]. Drifts in the baseline occurring due to scattering or fluorescence may be corrected using different approaches such as asymmetric least squares [78], mixture models [79], polynomial filter [80, 81] and the rubber band method [82]. In the study conducted by Medippally et. al., rubber band baseline correction, Savitzky-Golay smoothing algorithm and vector-normalisation was performed on the raw Raman spectra of liquid plasma prior to post processing, in R based statistical software [50]. In studies aimed at early diagnosis of oral cancer using Raman spectroscopy by Sahu et. al.[83] and differentiation Meningioma by Mehta et. al.,[84], raw liquid serum spectra were baseline corrected using a fifth order polynomial function, smoothed using Savitzky-Golay algorithm and vector normalised in Matlab based statistical software. Fifth order polynomial background subtraction from the raw serum spectra and normalisation was also implemented in Matlab by Rohdeler et. al. [36] in their study to compare mid-IR and Raman spectroscopy in quantitative analysis of serum. Two different algorithms were used by the same group to 
perform pre-processing of spectra of serum spectra of ultrafiltrate [37]. Spectra originating from ultrafiltrate were scaled to the area under the water Raman band at $1640 \mathrm{~cm}^{2}$ after determining the area by a Gaussian fit with linearly decreasing background from 1550 to 1770 $\mathrm{cm}^{2}$. In the case of serum, spectra were scaled to the maximum intensity and a fifth order polynomial background was subtracted. In their study to detect alterations in glucose and lipid components in the serum using near-IR Raman spectroscopy, Borges et. al.[85] fitted a seventh-order polynomial function over the $400-1800 \mathrm{~cm}^{-1}$ region and subtracted from the raw serum spectrum to remove the unwanted background, providing an effective baseline correction, and spectra were normalised by the area under the curve prior to data analysis. Least squares fitting was used by Berger et al. to remove the background mathematically by subtraction of a sloped straight line from each serum spectrum without affecting the shape of the Raman peaks [86]. Jenkins et. al. subjected the raw Raman spectra of serum to wavenumber standardisation, background subtraction using a rolling circle filter algorithm and normalisation to the peak at $1004 \mathrm{~cm}^{-1}$ [29]. The phenyl alanine peak was chosen for normalisation as it is the sharpest and most intense peak within the serum spectra and it is observed that normalisation to this peak produced better diagnostic discriminatory results when compared to other normalisation methods such as vector normalisation.

Although the accepted dogma is that the contribution of water to Raman spectra is significantly less than to mid-IR spectra, water still has a significant contribution to the Raman signatures in the fingerprint region of bodily fluids, due to the $\mathrm{OH}$ stretching vibration at $1640 \mathrm{~cm}^{-1}$. Analysis of the ultracentrifugation concentrate reduced the relative contribution of the water signal [68] but further efforts to remove it by data preprocessing have been explored, to increase the relative contribution of the analyte. Kerr et al., [87] have compared a number of commonly employed data pre-processing techniques, and, especially in the case where the background contains a known interferent, such as substrate or background, demonstrate the benefits of the 
adapted EMSC model, which also contains a polynomial with linear and higher order components. Parachalil et al. adopted an adapted method of Extended Multiplicative Signal Correction (EMSC) [87] to subtract the known spectrum of water from their spectra, initially for the analysis of the HMWF in simulated plasma mixtures [44], and subsequently the measurement protocol was used to quantitatively monitor diagnostically relevant changes of glucose in liquid serum samples (spiked serum samples and patient samples), and the results were compared with similar analysis protocols using infrared spectroscopy of dried samples [43]. The analysis protocols to detect the imbalances in glucose using Raman spectroscopy were first demonstrated for aqueous solutions and spiked serum samples. As in the case of infrared absorption studies [40], centrifugal filtration was utilised to deplete abundant analytes and to reveal the spectral features of LMWF analytes, in order to improve spectral sensitivity and detection limits. After the depletion of the abundant proteins, the dominant water peak from the filtrate collected after centrifugal filtration using $10 \mathrm{kDa}$ can be removed by using the EMSC algorithm, and PLSR analysis applied to obtain a prediction model relating the glucose concentrations and the intensity of glucose features. Note, that the study introduced a water normalisation factor into the EMSC protocol, using the fitted co-efficient of the water scaling factor, which has the effect of scaling the analyte spectra, assuming a constant water contribution to all sample spectra. This step helps to considerably reduce the spectral variability of the Raman spectra of glucose recorded from 25 patient samples (Figure 3) [44].

The principle of EMSC for subtraction of a specific measureable background spectrum and the associated Matlab codes have previously been published by Kerr and Hennelly, 2016 [86], and their description is adapted in the following. The raw spectrum, S, consists of Raman spectrum of interest, R, a baseline signal, $\mathrm{B}$, and the water signal, $\mathrm{W}$.

$\mathrm{S}=\mathrm{R}+\mathrm{B}+\mathrm{W}[86]$ 
The Raman spectrum of interest can be represented by a reference spectrum of the material of interest, $r$, and it can be assumed that $\mathrm{R}$ is the product of this reference spectrum and a certain scalar weight, $C_{r}$, which describes the concentration dependence $[88,89]$

$\mathrm{R} \sim C_{r} \mathrm{X} \mathrm{r} \quad[86]$

Similarly, a spectrum, w, is recorded from water directly in order to represent the spectral contribution of water in $\mathrm{W}$, as the product of pure water spectrum and a certain scalar weight.

$\mathrm{W}=C_{w} \mathrm{x} \mathrm{W} \quad[86]$

The baseline, B, is now represented by an appropriate order of polynomial $(N)$ as:

$\mathrm{B}_{N}=C_{0}+C_{1} \mathrm{X}+C_{2} \mathrm{X}^{2}+\ldots \ldots+C_{N} \mathrm{X}^{\mathrm{N}} \quad[86]$

where $N$ is the order of polynomial and $C_{\mathrm{m}}$ for $\mathrm{m}=0 \rightarrow \mathrm{N}$ represents various coefficients of polynomial. The EMSC algorithm is used to obtain estimates of the scalar values $C_{r}, C_{m}$ and $C_{w}$. These estimates are obtained from an optimal fit of the various vectors in Equation 5.

$\mathrm{S} \sim\left[C_{r} \times r\right]+\left[C_{w} \times w\right]+\left[\sum_{m=0}^{N} C_{m} X^{m}\right] \quad[86]$

The background corrected, concentration dependent analyte spectra, T, can be represented as:

$\mathrm{T}=\frac{\mathrm{S}-\left[C_{w} \times w\right]-\left[\sum_{m=0}^{N} C_{m X} m\right]}{C_{w}} \quad[86]$

Note, that division by $C_{w}$ has the effect of scaling the analyte spectra, assuming a constant water contribution to all sample spectra. 

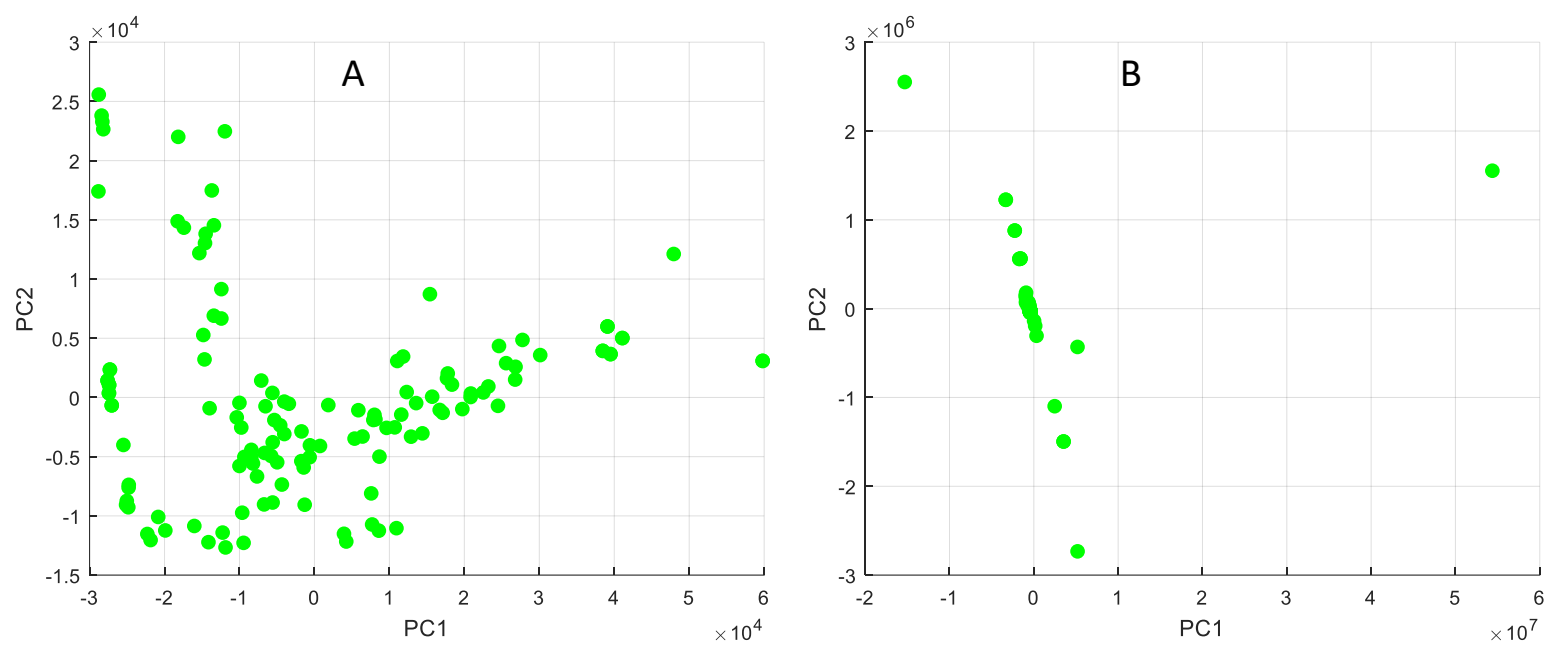

Figure 3. (A) PCA scatter plot of Raman data of the filtrate obtained after ultrafiltration of patient serum without scaling the analyte (glucose) spectra from the previously published study by Parachalil et. al [44] and (B) after scaling the analyte spectra to the water content. Figure 3B displays less scatter when compared to Figure 3A, indicating less variability among the spectra

However, although the EMSC algorithm removed the underlying water spectra effectively, interference from other LMWF analytes, namely, urea was noticed. Hence, a shorter spectral range from $1030 \mathrm{~cm}^{-1}$ to $1400 \mathrm{~cm}^{-1}$ was chosen for data analysis, as this region does not contain signature peaks of urea. Improved Root RMSECV was observed for Raman prediction models, whereas slightly higher $\mathrm{R}^{2}$ values were reported for infrared absorption prediction models.

The adapted EMSC algorithm can also be employed to remove known spectral interferents. In several studies of human serum, $\beta$-carotene has been observed as a string contributor to the spectrum, particularly when using $532 \mathrm{~nm}$ or lower as source, as the scattering from the conjugated antioxidant species are resonantly enhanced $[29,50,83]$. The LMWF species are not easily removed by centrifugal separation [69], but their contributions can be effectively “digitally" removed using the adapted EMSC protocol.

\section{Data Analysis}


Data analysis protocols can be differentiated into classification protocols, largely employed for diagnostic purposes, and regression protocols, predominantly used for quantitation of identified analytes. The latter have been explored for both imbalances in intrinsic blood constituents, as well as for therapeutic drug monitoring.

Depciuch et al. collected Raman and FTIR spectra from dried and liquid serum from depressed patients and their analysis indicated that both methods provided equally valid results to discriminate the patients with similar accuracies [33]. The light source wavelength was $780 \mathrm{~nm}$ and the sample volume used was $1.5 \mathrm{ml}$, which could be an impediment for clinical translation. Other similar studies conducted by the same group using the same set up on phospholipidprotein balance in human serum and qualitative, quantitative changes in phospholipids and proteins in animal depression models. The role of zinc deficiency induced phospholipid-protein imbalance in serum of the animal models suggest that both IR and Raman spectroscopic techniques could be used as effective tools to identify the changes in the blood serum [30-32]. To investigate similarities and differences between the serum samples of different types of depression in humans, Principal Components Analysis-Linear Discriminant Classification (PCA-LDC) was employed in their analysis of Raman and FTIR spectra from dried and liquid serum from depressed patients [33]. The results from both FTIR and Raman spectra unambiguously demonstrated that the levels of proteins and phospholipids are higher in healthy controls than in depressed subjects and that phospholipids affect the structure of proteins. Two measurement strategies were compared in order to determine the influence of water on the measured spectra; the first method entailed recording the water spectrum as back-ground, and subsequently automatically subtracting it from each serum spectrum, while the second method entailed recording a spectrum of the air prior to the spectrum of blood serum and subsequently the water spectrum was subtracted from the blood serum without air background. Both the methods provided identical serum spectra, suggesting that appropriate measurement of the 
background and the subtraction of water signal had the greatest impact on the reliability of the results.

Jenkins et al. developed a high-throughput (HT) serum Raman spectroscopy platform and compared dry and liquid data acquisition of serum samples for liquid biopsy of 30 colorectal cancer patients and 30 matched control patients [29]. Using a stainless steel high throughput substrate that allows up to 40 samples to be loaded at once, and $785 \mathrm{~nm}$ laser as the excitation wavelength, the maximum sensitivity and specificity obtained for discrimination of colorectal cancer patients were $77 \%$ and $81 \%$ respectively. In this study, Raman spectra were subjected to routine preprocessing such as wavenumber standardisation, background subtraction using a rolling circle filter algorithm and normalisation to the peak at $1004 \mathrm{~cm}^{-1}$. Partial least squares discriminant analysis (PLS-DA) was used to investigate causes of differences and variances within datasets. PLS-DA models were cross validated using k-fold cross validation with 5 folds. The sample volume required was $200 \mu \mathrm{L}$ and the total time for the data collection was 12.5min. In a clinical setting, it would be advantageous to reduce the data collection time in order to avoid delay in analysis. When excitation wavelength of $532 \mathrm{~nm}$ was used on the liquid platform, the specificity was found to be low, due to the prominence of carotenoids in the serum spectra. No measures were taken to remove the interference of carotenoids from the spectral data. The prominence of carotenoids due to resonance Raman was also reported by Sahu et al., in an exploratory study for detection of oral cancers [83] and by Mehta et al., in their study conducted to differentiate meningioma. Sahu et. al. used 532nm as excitation source and Raman spectra were collected by placing $30 \mu \mathrm{L}$ serum samples on a glass slide and the laser was focused through a 50X Nikon objective. The spectra were vector normalised, baseline corrected, smoothed and subjected to PCA-LDA followed by cross-validation using leave-oneout cross-validation (LOOCV). Although this study reported spectral differences between DNA, changes in the plasma amino acid profiles and $\beta$-carotene levels across the analysed 
groups, the strong bands of $\beta$-carotene could interfere with the detection of other analytes increasing the ambiguity in the results obtained. In the study conducted by Mehta et al., 25 patient samples from healthy and meningioma groups were subjected to PC and PC-LDA followed by LOOCV cross validation, yielding classification efficiency of $92 \%$ and $80 \%$ for healthy and meningioma respectively. Passively thawed $30 \mu \mathrm{L}$ serum samples, on a calcium fluoride $\left(\mathrm{CaF}_{2}\right)$ slides were subjected to Raman analysis using $785 \mathrm{~nm}$ laser excitation source. Borges et al.[85], collected blood serum from 44 volunteers to discriminate between altered and normal concentrations of glucose, total cholesterol, triglycerides, low density (HDL) and high density lipoproteins (LDL). Raman analysis was performed using 830nm excitation source for a sample volume of $100 \mu \mathrm{L}$. The data collected was subjected to PCA yielding a classification efficiency of $77 \%$ for total cholesterol, $81 \%$ for triglycerides, $59 \%$ for HDL and $60 \%$ for LDL.

In terms of quantification of systematically variable analyte concentrations, multivariate PLSR analysis is often the method of choice. PLSR is most commonly employed to construct a model that can relate variations of the measured spectral responses to a systematic variation of concentrations of the target analyte [90-92]. The constructed model can them be employed to identify spectral factors which account for the maximum variation in predictors ' $\mathrm{X}$ ' (spectral data) versus associated responses ' $\mathrm{Y}$ ' (target values of protein concentration) [91]. The spectral data (X matrix) can thus be related to the target concentrations (Y matrix) according to the linear relationship $\mathrm{Y}=\mathrm{XB}+\mathrm{E}$, in which $\mathrm{B}$ and $\mathrm{E}$ are matrices of regression coefficients and residuals, respectively. The PLSR model can be used to predict the outcome of varying concentration of analytes based on the spectral data. The model is validated using a rigorous cross validation procedure which evaluates its performance in accurately predicting analyte concentrations [44]. In the study of Berger et al., PLSR prediction models were built, using leave one out cross validation (LOOCV), for each the six analytes after spectral background 
removal, providing an root mean square error of $26 \mathrm{mg} / \mathrm{dL}, 12 \mathrm{mg} / \mathrm{dL}, 29 \mathrm{mg} / \mathrm{dL}, 3.8 \mathrm{mg} / \mathrm{dL}$, $0.19 \mathrm{mg} / \mathrm{dL}$ and $0.12 \mathrm{mg} / \mathrm{dL}$ for glucose, cholesterol, triglyceride, urea, total protein and albumin, respectively [28]. A similar approach was employed by Parachalil et al. [43] to compare the predictive capacity of Raman microscopy for quantitation of glucose in human serum, compared to the similar ATR-FTIR analysis of Bonnier et al. [87] indicating that the RMSECV for Raman of $1.84 \mathrm{mg} / \mathrm{dL}$ is comparable or better than that of $3.1 \mathrm{mg} / \mathrm{dL}$ for ATRFTIR.

Having removed the spectral interferents using EMSC, PLSR can independently identify spectral correlation associated with target analyte range. Cross-validation of the PLSR model is required to evaluate the accuracy, often cited in terms of the Root Mean Square Error of Cross Validation (RMSECV) [93]. The number of latent variables used for construction of the PLSR model is optimised by establishing the value that is equivalent to the minimum of the RMSECV. The $\mathrm{R}^{2}$ value provides an indication of the correlation between the analyte concentration and spectral intensity, while the standard deviation (STD) provides an indication of the variation between each spectrum calculated from the same sample. Commonly, a multiple fold cross validation approach is employed to validate the robustness of the method. Typically, the set of observations is randomly divided into approximately equal size, e.g. 50\% of the spectral data randomly selected as test set, while the remaining $50 \%$ is used as the training set [101]. The cross-validation process is then repeated multiple times (the folds), such that all observations are used for both training and testing, and each observation is used for testing exactly once. The results from the folds can then be averaged to produce a single estimation. The Root Mean Square Error of Cross Validation (RMSECV) is calculated from the multiple iterations to measure the performance of the model for the unknown cases within the calibration set. 
In order to advance the studies of Berger et al., [86] and Rohleder et al.,[36, 37] using the improved inverted microscopy modality, Parachalil et al.[69] also used the EMSC correction, ultrafiltration protocols and PLSR analysis to construct models for the quantitation of the whole serum (total protein, $\gamma$ globulin), serum concentrate (albumin) and serum filtrate (urea and glucose) of patient samples, resulting in higher accuracy and sensitivity of analysis. The strategy demonstrated in this study enables the simultaneous estimation of total protein level and detection of imbalance in $\gamma$ globulin concentration accurately from whole serum, without the use of any reagents and without destroying the sample being studied. The proposed method has many advantageous over the routinely used biuret method, Turbidimetric Immunoassay (TIA) and Radial Immunodiffusion (RID), as the required sample volume can be as low as $10 \mu \mathrm{L}$, it is rapid and non-destructive to the medium being studied, whereas the conventional methods are considered impractical due to the requirement of large sample volume and laborious sample processing steps [94-96]. Moreover, the linearity reported for a comparative study of RID and TIA is 0.59 [97], substantially lower than the $\mathrm{R}^{2}$ calculated by Parachalil et al. [44]. Using filtration, the albumin was isolated from patient serum and the prediction model had a prediction accuracy significantly superior to that reported for the Bromoscerol Green method (2.2 $\mathrm{g} / \mathrm{dL})$, used to determine albumin concentrations from cirrhotic patients [98]. It has previously been reported that selecting the spectral region from $1030 \mathrm{~cm}^{-1}$ to $1400 \mathrm{~cm}^{-1}$ improved the sensitivity and specificity for the prediction model of glucose from patient samples over the concentration range 52.5-434.2 $\mathrm{mg} / \mathrm{dL}$, and the technique was demonstrated to be at least as accurate as ATR-FTIR of similar patient samples [69], measured in the dried state and closer to the accuracy of colorimetric methods, $1.4 \mathrm{mg} / \mathrm{dL}$ urea [99] and $2 \mathrm{mg} / \mathrm{dL}$ glucose [100]. Similarly, higher prediction accuracy (RMSECV=1.14 mg/dL) was attained when PLSR analysis was performed on a reduced range for urea from patient samples over the concentration range $2.52-78.99 \mathrm{mg} / \mathrm{dL}$, compared to the full range (RMSECV=1.73 $\mathrm{mg} / \mathrm{dL}$ ). 
This standardised, optimised methodology was also applied to determine the Limit of Detection (LOD) and Limit of Quantification (LOQ) for therapeutic drug monitoring (TDM) in human serum, using the examples of Busulfan, a cell cycle non-specific alkylating antineoplastic agent, and, Methotrexate, a chemotherapeutic agent and immune system suppressant [101]. Ultrafiltration of the spiked human pooled serum with $10 \mathrm{kDa}$ centrifugal filter efficiently recovered the drug in the filtrate prior to performing Raman analysis. The drug concentration ranges were chosen to encompass the recommended therapeutic ranges and toxic levels in patients. Finally, prediction models were built by using PLSR and LOD and LOQ were calculated directly from the linear prediction models. The LOD calculated for Busulfan is $0.0002 \pm 0.0001 \mathrm{mg} / \mathrm{mL}, 30-40$ times lower than the level of toxicity, enabling the application of this method in target dose adjustment of Busulfan for patients undergoing, for example, bone marrow transplantation. The LOD and LOQ calculated for Methotrexate are $7.8 \pm 5 \mu \mathrm{M}$ and $26 \pm 5 \mu \mathrm{M}$, respectively, potentially enabling high dose monitoring. Although SERS gives promising results in detecting drugs at low concentrations in biological matrices [16, 102], qualitative variations within the SERS substrate, and the interference of other biomolecules with the SERS spectra, makes quantification in real samples a challenging task [103]. The simpler approach, adopted here, of Raman spectroscopy coupled with concentration of the high and low molecular weight serum fractions using commercially available centrifugal filter devices and multivariate analysis technique ensures that the information in the fractions is effectively preserved, while enabling easy detection of the analyte concentration with higher accuracy that in the unprocessed sample. Better analysis of serum using Raman spectroscopy was observed when the sample was analysed in the inverted geometry using the water immersion objective with a 532nm laser as source with Lab-Tek plate as substrate [44]. A drop of water is used to minimise the differences in the refractive indexes between sample, objective and the substrate. However, the water drop does not contribute to the data collected, as it is 
outside the focus of the beam. The promising results from the systematic studies conducted by Parachalil et al.[69] using this analytical set up combined with chemometric techniques such as EMSC to measure concentrations of HMWF, LMWF and drugs in human serum strongly indicates a highly significant correlation between predicted and reference concentrations. These results suggest that Raman can on its own can detect and quantify concentrations close to $1 \%$ without the aid of any enhancement method [37].

Considering the more general applications of the technique to a broader range of drugs or analytes, it is notable that both the LOD and LOQ for a given set up are determined by the STD of the measurement of the control (serum or filtered serum), and the Raman scattering efficiency of the analyte. To further illustrate this point, the LOD of vitamin B12, cholesterol, urea and glucose from liquid samples for this measurement protocol were also determined using the method previously reported by Parachalil et al. [101] (Table 1). Figure 4 displays a plot of LOD versus the maximum intensity per unit acquisition time, per unit concentration. An approximately linear, inverse relationship can be seen, which simply emphasises the maxim that the stronger the Raman signal of the analyte, the easier it is to detect. The correlation also implies, however, that a simple measurement of the analyte in aqueous solution could be employed to predict the LOD, and therefore the suitability of the technique for the therapeutic monitoring application. 
Table 1: LOD of glucose [44], busulfan [101], methotrexate [101], cholesterol, urea [69] and vitamin B12 calculated from the PLSR prediction plot of these analytes, compared to the maximum Raman intensity of maximum peak per unit acquisition time, per unit concentration

\begin{tabular}{|l|l|l|}
\hline Analyte & Intensity & LOD(mM) \\
& arb. & \\
units $)$ & \\
\hline Glucose & 1000 & $0.0006 \pm 0.0005$ \\
\hline Busulfan & 19704 & $0.0008 \pm 0.0001$ \\
\hline MTX & 1600 & $0.00076 \pm 0.0005$ \\
\hline Cholesterol & 216718 & $0.0006 \pm 0.0001$ \\
\hline Urea & 540000 & $0.00033 \pm 0.00001$ \\
\hline VB12 & 1266666 & $0.00014 \pm 0.00002$ \\
\hline
\end{tabular}

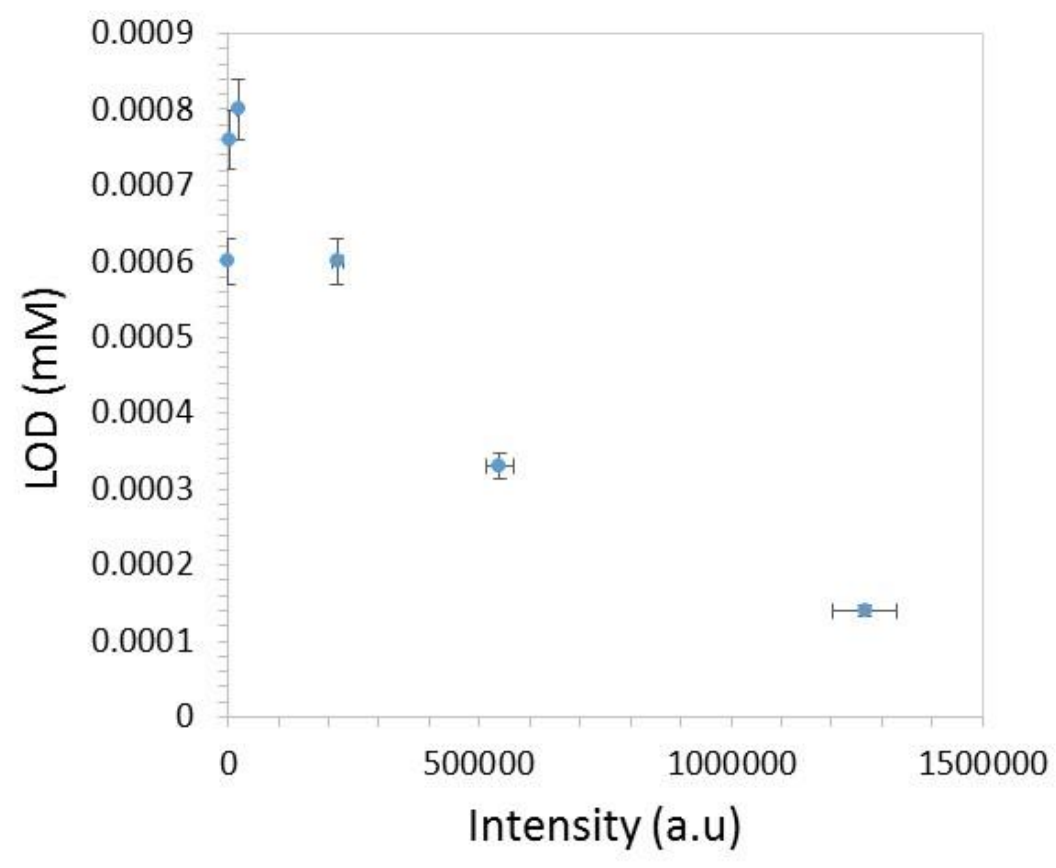

Figure 4. LOD of glucose (44), urea (69), busulfan (101), methotrexate (101), cholesterol, and vitamin B12 calculated from the PLSR prediction plot of these analytes, compared to the 'maximum Raman intensity of maximum peak per unit acquisition time, per unit concentration'. The methodology used for calculating LOD was previously published (101) 


\section{Clinical Translation}

Vibrational spectroscopic techniques have attracted a lot of attention as analytical methods of choice for analysing biological samples. The promise of the techniques is based on the abilities to objectively fingerprint the biochemical profile underlying early onset of disease in cells, tissues or bodilyfluids $[3,6,9]$. The techniques have no requirement of specific reagent, and the minimal sample preparation means there should be fewer procedural errors and no major time delay in providing the results to the patients. In the case of FTIR, considerable progress towards using this technique as a routine diagnostic tool for disease diagnosis has been made. Recently, ClinSpec Diagnostic, based at the University of Strathclyde's Technology \& Innovation Centre, won a $£ 1.2$ million investment to further develop a "revolutionary" blood test using FTIR which could potentially improve brain cancer survival rates through early detection of the disease [104]. Researchers from Monash University have similarly developed FTIR based techniques to analyse disease-causing pathogens in human blood [105]. Advances in instrumentation have made FTIR an ideal tool of choice for an increasing number of clinical application even though the sample drying step is potentially a huge drawback $[19,68,106]$. Notably, it is demonstrated that the Raman analysis protocol can yield accuracies which are comparable with those reported using infrared absorption based measurements of dried serum, without the need for additional drying steps. However, there remain challenges to fulfilling the requirements for clinical translation. Distortions in the spectra due to the water contributions, low detectability of the low molecular weight fraction analytes, lack of standardisation steps and financial factors could be the hindrance for clinical translation in the medical and clinical environment. Nevertheless, new strategies have been recently developed to address these potential limitations, namely the inverted Raman geometry, low cost (Lab-Tek plate) substrates, serum fractionation techniques, selective spectral region analysis and sophisticated data preprocessing (EMSC) and analysis (PLSR) techniques. These advances have maximised 
the diagnostic accuracy and are cost-effective solutions that are likely to be adopted in a clinical setting.

Application of the adapted EMSC based algorithm helped to eliminate the contribution from water and scattering associated with the HMWF, and linear predictive models were built from the PLSR analysis. It is worth noting that PLSR seeks to correlate systematic variations in the spectroscopic profiles with the external target variable, in this case protein concentration. As such, the method is not inherently specific to any molecular variations, in the case where multiple species vary simultaneously over the same range. The accuracy of the proposed method is comparable to that of the most commonly used method for detecting albumin from biological fluids, the Enzyme Linked Immunosorbent Assay (ELISA) [107, 108], and the most commonly used gold-standard method i.e., the Clauss assay for fibrinogen [109]. The proposed approach can be expeditiously employed for early detection of pathological disorders associated with high or low plasma/serum analytes.

Bodily fluids are usually collected from a large number of patients in a hospital, potentially delaying the performance of the analysis and availability of results, which may in turn delay the therapy, and prolong patient anxiety. The accuracy of the conventional test kits that enable point-of-care testing can be poor, and they are can be avoided due to high cost $[110,111]$. The enormous advantage of employing this inverted Raman spectral analysis for real-time serum/plasma analysis in a clinical setting is that, in the face of emerging diseases, one could get an early diagnosis in a cost effective manner before the disease becomes symptomatic (Figure 1). Integrated with smaller spectroscopic instrumentation, implementation of such a screening/diagnostic tool in developing countries where conventional diagnostics methods are scarce and avoided due to high cost, would bring about a dramatic impact on population screening. 


\section{Conclusion}

The potential advantages of employing Raman spectroscopy of bodily fluids for disease diagnosis apart from its high sensitivity and specificity are: low cost, no reagents are required, samples can be probed in the native state and rapid results can be obtained. Although there is a wealth of information to support the application of Raman analysis for bodily fluids, this approach is still considered young and upcoming in the eyes of medical community, thereby hindering its clinical translation. The examples summarised in this article attest to the cost effective, easy to use, reproducible method of Raman measurement protocol for detecting imbalances in serum/plasma proteins and low molecular weight analytes, as well as therapeutic drug monitoring. Significantly improved sensitivity of Raman spectroscopic measurements of blood samples in liquid form is achievable by means of serum fractionation and the implementation of chemometric approaches. In the case of clinical translation, there remain challenges to overcome before it can be a reality. Nevertheless, it has been demonstrated that options and alternatives are available to overcome these challenges in using Raman spectroscopy for liquid sample analysis, leading to a better accuracy and repeatability and thus a better sensitivity. Naturally, the next phase includes not only refining this method and improving the technical capabilities to match those of the current clinical needs, but also technical advances to translate them from research laboratory to clinical practice. In addition, to ensure further relevancy of this method, comparison studies between the gold standard of current diagnostic methods and the current method in a large multi-centred randomised clinical trials are required. Once these factors are taken into account, it is possible to envisage a routine platform providing clinical biochemical analysis at minimal cost.

\section{Conflicts of interest}

There are no conflicts to declare. 


\section{Acknowledgements}

Drishya Rajan Parachalil was funded by DIT Fiosraigh scholarship. J. McIntyre was funded by Science Foundation Ireland, PI/11/08.

\section{References}

1. Hughes C, Brown M, Clemens G, Henderson A, Monjardez G, Clarke NW, Gardner P (2014) Assessing the challenges of Fourier transform infrared spectroscopic analysis of blood serum. J Biophotonics 7:180-188 . https://doi.org/10.1002/jbio.201300167

2. Baker MJ, Hughes CS, Hollywood KA (2016) Biophotonics: Vibrational Spectroscopic Diagnostics. Morgan \& Claypool Publishers

3. Baker MJ, Hussain SR, Lovergne L, Untereiner V, Hughes C, Lukaszewski RA, Thiéfin G, Sockalingum GD (2015) Developing and understanding biofluid vibrational spectroscopy: a critical review. Chem Soc Rev 45:1803-1818 . https://doi.org/10.1039/c5cs00585j

4. Hughes C, Baker MJ (2016) Can mid-infrared biomedical spectroscopy of cells, fluids and tissue aid improvements in cancer survival? A patient paradigm. Analyst 141:467475

5. Kong K, Kendall C, Stone N, Notingher I (2015) Raman spectroscopy for medical diagnostics - From in-vitro biofluid assays to in-vivo cancer detection. Adv. Drug Deliv. Rev. 89

6. Bunaciu AA, Fleschin Ş, Hoang VD, Aboul-Enein HY (2017) Vibrational Spectroscopy in Body Fluids Analysis. Crit Rev Anal Chem 47:67-75 . https://doi.org/10.1080/10408347.2016.1209104

7. Shaw RA, Low-Ying S, Man A, Liu K-Z, Mansfield C, Rileg CB, Vijarnsorn M (2007) Infrared Spectroscopy of Biofluids in Clinical Chemistry and Medical 
Diagnostics. In: Biomedical Vibrational Spectroscopy. John Wiley \& Sons, Inc., pp $79-103$

8. Byrne HJ, Baranska M, Puppels GJ, Stone N, Wood B, Gough KM, Lasch P, Heraud P, Sulé-Suso J, Sockalingum GD (2015) Spectropathology for the next generation: quo vadis? Analyst 140:2066-73 . https://doi.org/10.1039/c4an02036g

9. Mitchell AL, Gajjar KB, Theophilou G, Martin FL, Martin-Hirsch PL (2014) Vibrational spectroscopy of biofluids for disease screening or diagnosis: Translation from the laboratory to a clinical setting. J Biophotonics 7:153-165 . https://doi.org/10.1002/jbio.201400018

10. Eberhardt K, Stiebing C, Matthäus C, Schmitt M, Popp J (2015) Advantages and limitations of Raman spectroscopy for molecular diagnostics: an update. Expert Rev Mol Diagn 15:773-87 . https://doi.org/10.1586/14737159.2015.1036744

11. Roy S, Perez-Guaita D, Andrew DW, Richards JS, McNaughton D, Heraud P, Wood BR (2017) Simultaneous ATR-FTIR Based Determination of Malaria Parasitemia, Glucose and Urea in Whole Blood Dried onto a Glass Slide. Anal Chem 89:5238-5245 . https://doi.org/10.1021/acs.analchem.6b04578

12. Perez-Guaita D, Ventura-Gayete J, Pérez-Rambla C, Sancho-Andreu M, Garrigues S, De La Guardia M (2012) Protein determination in serum and whole blood by attenuated total reflectance infrared spectroscopy. Anal Bioanal Chem 404:649-656 . https://doi.org/10.1007/s00216-012-6030-7

13. Spalding K, Bonnier F, Bruno C, Blasco H, Board R, Benz-de Bretagne I, Byrne HJ, Butler HJ, Chourpa I, Radhakrishnan P, Baker MJ (2018) Enabling quantification of protein concentration in human serum biopsies using attenuated total reflectance Fourier transform infrared (ATR-FTIR) spectroscopy. Vib Spectrosc 99:50-58 . https://doi.org/10.1016/j.vibspec.2018.08.019 
14. Paraskevaidi M, Morais CLM, Lima KMG, Snowden JS, Saxon JA, Richardson AMT, Jones M, Mann DMA, Allsop D, Martin-Hirsch PL, Martin FL (2017) Differential diagnosis of Alzheimer's disease using spectrochemical analysis of blood. Proc Natl Acad Sci U S A 114:E7929-E7938 . https://doi.org/10.1073/pnas.1701517114

15. Yang J, Tan X, Shih WC, Cheng MMC (2014) A sandwich substrate for ultrasensitive and label-free SERS spectroscopic detection of folic acid / methotrexate. Biomed Microdevices 16:673-679 . https://doi.org/10.1007/s10544-014-9871-3

16. Fornasaro S, Marta D, Rabusin M (2016) Toward SERS-based point-of-care approaches for therapeutic drug monitoring : the case of methotrexate. Faraday Discuss 00:1-15 . https://doi.org/10.1039/C5FD00173K

17. Panikar SS, Ramírez-García G, Sidhik S, Lopez-Luke T, Rodriguez-Gonzalez C, Ciapara IH, Castillo PS, Camacho-Villegas T, De La Rosa E (2019) Ultrasensitive SERS Substrate for Label-Free Therapeutic-Drug Monitoring of Paclitaxel and Cyclophosphamide in Blood Serum. Anal Chem 91:2100-2111 . https://doi.org/10.1021/acs.analchem.8b04523

18. Hands JR, Abel P, Ashton K, Dawson T, Davis C, Lea RW, McIntosh AJS, Baker MJ (2013) Investigating the rapid diagnosis of gliomas from serum samples using infrared spectroscopy and cytokine and angiogenesis factors. Anal Bioanal Chem 405:73477355 . https://doi.org/10.1007/s00216-013-7163-z

19. Cameron JM, Butler HJ, Palmer DS, Baker MJ (2018) Biofluid spectroscopic disease diagnostics: A review on the processes and spectral impact of drying. J Biophotonics 11:1-12 . https://doi.org/10.1002/jbio.201700299

20. Lord RC, Yu NT (1970) Laser-excited Raman spectroscopy of biomolecules. I. Native lysozyme and its constituent amino acids. J Mol Biol 50:509-524

21. Tobin MC (1968) Raman spectra of crystalline lysozyme, pepsin, and alpha 
chymotrypsin. Science 161:68-69

22. Walton AG, Deveney MJ, Koenig JL (1970) Raman spectroscopy of calcified tissue. Calcif Tissue Res 6:162-167

23. Gniadecka M, Wulf HC, Nielsen OF, Christensen DH, Hercogova J (1997) Distinctive molecular abnormalities in benign and malignant skin lesions: studies by Raman spectroscopy. Photochem Photobiol 66:418-423

24. Breve GJP and J (1986) R. J. H. Clark and R. E. Hester (Editors). Advances in infrared and Raman spectroscopy, vol. 12. Wiley, New York. 1985. J Raman Spectrosc 17:487 . https://doi.org/10.1002/jrs.1250170613

25. Smith J, Kendall C, Sammon A, Christie-Brown J, Stone N (2003) Raman spectral mapping in the assessment of axillary lymph nodes in breast cancer. Technol Cancer Res Treat 2:327-332 . https://doi.org/10.1177/153303460300200407

26. Hanlon EB, Manoharan R, Koo TW, Shafer KE, Motz JT, Fitzmaurice M, Kramer JR, Itzkan I, Dasari RR, Feld MS (2000) Prospects for in vivo Raman spectroscopy. Phys Med Biol 45:R1-59

27. Caspers PJ, Lucassen GW, Wolthuis R, Bruining HA, Puppels GJ (1998) In vitro and in vivo Raman spectroscopy of human skin. Biospectroscopy 4:S31-9 . https://doi.org/10.1002/(sici)1520-6343(1998)4:5+<s31::aid-bspy4>3.0.co;2-m

28. Berger AJ, Koo T-W, Itzkan I, Horowitz G, Feld MS (1999) Multicomponent blood analysis by near-infrared Raman spectroscopy. Appl Opt 38:2916 . https://doi.org/10.1364/ao.38.002916

29. Jenkins CA, Jenkins RA, Pryse MM, Welsby KA, Jitsumura M, Thornton CA, Dunstan PR, Harris DA (2018) A high-throughput serum Raman spectroscopy platform and methodology for colorectal cancer diagnostics. Analyst 143:6014-6024 . https://doi.org/10.1039/c8an01323c 
30. Depciuch J, Sowa-kucma M, Nowak G, Papp M, Gruca P, Misztak P, Parlinska-wojtan M (2017) Spectrochimica Acta Part A : Molecular and Biomolecular Spectroscopy Qualitative and quantitative changes in phospholipids and proteins investigated by spectroscopic techniques in animal depression model. Spectrochim Acta Part A Mol Biomol Spectrosc 176:30-37 . https://doi.org/10.1016/j.saa.2016.12.007

31. Depciuch J, Nowak G, Szewczyk B, Doboszewska U (2020) ScienceDirect The role of zinc deficiency-induced changes in the phospholipid-protein balance of blood serum in animal depression model by Raman , FTIR and UV - vis spectroscopy. 89:549-558 . https://doi.org/10.1016/j.biopha.2017.01.180

32. Depciuch J, Sowa-ku M, Nowak G, Dudek D, Parli M (2016) Journal of Pharmaceutical and Biomedical Analysis Phospholipid-protein balance in affective disorders : Analysis of human blood serum using Raman and FTIR spectroscopy . A pilot study. 131:287-296 . https://doi.org/10.1016/j.jpba.2016.08.037

33. Depciuch J, Parlinska-Wojtan M (2018) Comparing dried and liquid blood serum samples of depressed patients: An analysis by Raman and infrared spectroscopy methods. J Pharm Biomed Anal 150:80-86 . https://doi.org/10.1016/j.jpba.2017.11.074

34. Sato-Berrú RY, Araiza-Reyna EA, Vazquéz-Olmos AR (2016) Moles quantification in liquid samples by Raman spectroscopy. Spectrochim Acta - Part A Mol Biomol Spectrosc 158:56-59 . https://doi.org/10.1016/j.saa.2016.01.017

35. Liu Z, Fan S, Liu H, Yu J, Qiao R, Zhou M, Yang Y, Zhou J, Xie P (2016) Enhanced detection of low-abundance human plasma proteins by integrating polyethylene glycol fractionation and immunoaffinity depletion. PLoS One 11:1-17 . https://doi.org/10.1371/journal.pone.0166306

36. Rohleder D, Kocherscheidt G, Gerber K, Kiefer W, Kohler W, Mocks J, Petrich W 
(2005) Comparison of mid-infrared and Raman spectroscopy in the quantitative analysis of serum. J Biomed Opt 10:31108 . https://doi.org/10.1117/1.1911847

37. Rohleder D, Kiefer W, Petrich W (2004) Quantitative analysis of serum and serum ultrafiltrate by means of Raman spectroscopy. Analyst 129:906-911 . https://doi.org/10.1039/b408927h

38. Kiefer W, Laane J (1980) Analytical Applications of FT-IR to Molecular and Biological Systems. Springer Netherlands, Dordrecht

39. Bonnier F, Brachet G, Duong R, Sojinrin T, Respaud R, Aubrey N, Baker MJ, Byrne HJ, Chourpa I (2016) Screening the low molecular weight fraction of human serum using ATR-IR spectroscopy. J Biophotonics 9:1085-1097 . https://doi.org/10.1002/jbio.201600015

40. Bonnier F, Blasco H, Wasselet C, Brachet G, Respaud R, Carvalho LFCS, Bertrand D, Baker MJ, Byrne HJ, Chourpa I (2017) Ultra-filtration of human serum for improved quantitative analysis of low molecular weight biomarkers using ATR-IR spectroscopy. Analyst 142:1285-1298 . https://doi.org/10.1039/c6an01888b

41. Smith E, Dent G (2004) The Raman Experiment - Raman Instrumentation, Sample Presentation, Data Handling and Practical Aspects of Interpretation. In: Modern Raman Spectroscopy - A Practical Approach. John Wiley \& Sons, Ltd, pp 23-70

42. Gerrard DL, Birnie J (1990) Raman Spectroscopy. Anal Chem 62:44-50 . https://doi.org/10.1021/ac00211a004

43. Parachalil DR, Bruno C, Bonnier F, Blasco H, Chourpa I, Baker MJ, McIntyre J, Byrne HJ (2019) Analysis of bodily fluids using vibrational spectroscopy: A direct comparison of Raman scattering and infrared absorption techniques for the case of glucose in blood serum. Analyst 144:3334-3346 . https://doi.org/10.1039/c9an00125e

44. Parachalil DR, Brankin B, McIntyre J, Byrne HJ (2018) Raman spectroscopic analysis 
of high molecular weight proteins in solution - considerations for sample analysis and data pre-processing. Analyst 143:5987-5998 . https://doi.org/10.1039/C8AN01701H

45. Leal LB, Nogueira MS, Canevari RA, Carvalho LFCS (2018) Vibration spectroscopy and body biofluids: Literature review for clinical applications. Photodiagnosis Photodyn. Ther. 24:237-244

46. Zhao Y, Ji N, Yin L, Wang J (2015) Research Article A Non-invasive Method for the Determination of Liquid Injectables by Raman Spectroscopy. 16:914-921 . https://doi.org/10.1208/s12249-015-0286-0

47. Shaw RA, Kotowich S, Leroux M, Mantsch HH (1998) Multianalyte Serum Analysis Using Mid-Infrared Spectroscopy. Ann Clin Biochem 35:624-632 . https://doi.org/10.1177/000456329803500505

48. Kerr LT, Byrne HJ, Hennelly BM (2015) Optimal choice of sample substrate and laser wavelength for Raman spectroscopic analysis of biological specimen. Anal Methods 7:5041-5052 . https://doi.org/10.1039/C5AY00327J

49. Fullwood LM, Griffiths D, Ashton K, Dawson T, Lea RW, Davis C, Bonnier F, Byrne HJ, Baker MJ (2014) Effect of substrate choice and tissue type on tissue preparation for spectral histopathology by Raman microspectroscopy. Analyst 139:446-454 . https://doi.org/10.1039/c3an01832f

50. Medipally DKR, Maguire A, Bryant J, Armstrong J, Dunne M, Finn M, Lyng FM, Meade AD (2017) Development of a high throughput (HT) Raman spectroscopy method for rapid screening of liquid blood plasma from prostate cancer patients. Analyst 142:1216-1226 . https://doi.org/10.1039/C6AN02100J

51. Nabers A, Perna L, Lange J, Mons U, Schartner J, Güldenhaupt J, Saum K, Janelidze S, Holleczek B, Rujescu D, Hansson O, Gerwert K, Brenner H (2018) Amyloid blood biomarker detects Alzheimer's disease. EMBO Mol Med 10:1-11 . 
https://doi.org/10.15252/emmm.201708763

52. Akao Y, Nakagawa Y, Hirata I, Iio A, Itoh T, Kojima K, Nakashima R, Kitade Y,

Naoe T, Balzar M, Winter MJ, de Boer CJ, Litvinov SV, Barnard F, Chen Y, Zhang H, Gou X, Horikawa Y, Xing JJ-L, Chen ZZ-NNZZ-N, Fassan M, Pizzi M, Giacomelli L, Mescoli C, Ludwig K, Pucciarelli S, Rugge M, Fong D, Seeber A, Terracciano L, Kasal A, Mazzoleni G, Lehne F, Gastl G, Spizzo G, Gaiser MR, Lammermann T, Feng X, Igyarto BZ, Kaplan DH, Tessarollo L, Germain RN, Udey MC, Gires O, Stoecklein NH, Goossens-Beumer IJ, Zeestraten ECM, Benard A, Christen T, Reimers MS, Keijzer R, Sier CFM, Liefers GJ, Morreau H, Putter H, Vahrmeijer a L, van de Velde CJH, Kuppen PJK, Hofsli E, Sjursen W, Prestvik WS, Johansen J, Rye M, Tranø G, Wasmuth HH, Hatlevoll I, Thommesen L, Holla VR, Backlund MG, Yang P, Newman R a., DuBois RN, Hong IK, Jin YJ, Byun HJ, Jeoung D Il, Kim YM, Lee HH, Huang ZZ, Huang D, Ni S, Peng Z, Sheng W, Du X, Ke X, Li L, Dong HL, Chen ZZ-NNZZN, Keller S, König AK, Marmé F, Runz S, Wolterink S, Koensgen D, Mustea A, Sehouli J, Altevogt P, Kuhn S, Koch M, Nübel T, Ladwein M, Antolovic D, Klingbeil P, Hildebrand D, Moldenhauer G, Langbein L, Franke WW, Weitz J, Zöller M, Li L, Tang W, Wu X, Karnak D, Meng X, Thompson R, Hao X, Li YYY, Qiao XT, Lin JJJ, Fuchs J, Simeone DM, Chen ZZ-NNZZ-N, Lawrence TS, Xu L, Xu J, Chen L, Zhong W De, Zhang Z, Mi L, Zhang Y, Liao CG, Bian HJ, Jiang J-LJ-LJL, Yang X-MM, Li XY, Fan CM, Zhu P, Fu L, Chen ZZ-NNZZ-N, Lin JJJ, Li J, Huang B, Liu J, Chen XX, Chen XX, Xu Y, Huang L, Wang XX, Lin P-C, Lin S-C, Lee C-T, Lin Y-J, Lee JC, Luo X, Stock C, Burwinkel B, Brenner H, Oberg AL, French AJ, Sarver AL, Subramanian S, Morlan BW, Riska SM, Borralho PM, Cunningham JM, Boardman L a., Wang LLLL, Smyrk TC, Asmann Y, Steer CJ, Thibodeau SN, Ogata-Kawata H, Izumiya M, Kurioka D, Honma Y, Yamada Y, Furuta K, Gunji T, Ohta H, Okamoto 
H, Sonoda H, Watanabe M, Nakagama H, Yokota J, Kohno T, Tsuchiya N, Ragusa M, Statello L, Maugeri M, Barbagallo C, Alhamdani MS, Destri GL, Cappellani A, Purrello M, Ralhan R, He HCH, So AKC, Tripathi SC, Kumar M, Hasan MR, Kaur J, Kashat L, Macmillan C, Chauhan SS, Freeman JL, Walfish PG, Runz S, Keller S, Rupp C, Stoeck A, Issa Y, Koensgen D, Mustea A, Sehouli J, Kristiansen G, Altevogt P, Sankpal N V, Mayfield JD, Willman MW, Fleming TP, Gillanders WE, Tang J, Guo Y-SYS, Zhang Y, Yu X-LXL, Li L, Huang W, Li YYY, Chen B, Jiang J-LJ-LJL, Chen ZZ-NNZZ-N, Tang Y, Kesavan P, Nakada MT, Yan L, Taylor DD, GercelTaylor C, Testa JE, Brooks PC, Lin JJJ, Wang JJ, Zhou Y, Lu J, Sun Y, Xiao H, Liu M, Tian L, Wang Q, Huang ZZ, Ni S, Xiao X, Xu Q, Wang LLLL, Huang D, Tan C, Sheng W, Du X, Weidle UH, Scheuer W, Eggle D, Klostermann S, Stockinger H, Welton JL, Khanna S, Giles PJ, Brennan P, Brewis I a, Staffurth J, Mason MD, Clayton A, Xu J, Xu H-Y, Zhang Q, Song F, Jiang J-LJ-LJL, Yang X-MM, Mi L, Wen N, Tian R, Wang LLLL, Yao H, Feng Q, Zhang Y, Xing JJ-L, Zhu P, Chen ZZNNZZ-N, Xu R, Greening DW, Rai A, Ji H, Simpson RJ, Yang C, Robbins PD, Yauch RL, Berditchevski F, Harler MB, Reichner J, Hemler ME, Yoshioka Y, Kosaka N, Konishi Y, Ohta H, Okamoto H, Sonoda H, Nonaka R, Yamamoto H, Ishii H, Mori M, Furuta K, Nakajima T, Hayashi H, Sugisaki H, Higashimoto H, Kato TT, Takeshita F, Ochiya T, Zhao L, Liu WW, Xiao J, Cao B, Wang SJS, Xiang J, Li Z, Lu S, Hu J, Gao X, Yu L, Wang LLLL, Wang JJ, Wu YY, Chen ZZ-NNZZ-N, Zhu H, Zhao P, Zhang W, Wang SJS, Yu X-LXL, Tang J, Huang W, Li YYY, Cui HY, Guo Y-SYS, Tavernier J, Zhang SH, Jiang J-LJ-LJL, Chen ZZ-NNZZ-N, Iacono KT, Brown AL, Greene MI, Saouaf SJ, Yoshioka Y, Kosaka N, Konishi Y, Ohta H, Okamoto H, Sonoda H, Nonaka R, Yamamoto H, Ishii H, Mori M, Furuta K, Nakajima T, Hayashi H, Sugisaki H, Higashimoto H, Kato TT, Takeshita F, Ochiya T, Muramatsu T, 
Miyauchi T, Tokuhara T, Hasegawa H, Hattori N, Ishida H, Taki T, Tachibana S, Sasaki S, Miyake M, Kohno M, Hasegawa H, Miyake M, Yamamoto T, Fujita S, Harouaka R, Kang Z, Zheng S-Y, Cao L, Belov L, Zhou J, Christopherson RI, Friedlander TW, Premasekharan G, Paris PL, Armstrong A, Eck SL, Trzpis M, McLaughlin PMJ, de Leij LMFH, Harmsen MC, Lin CW, Liao MY, Lin WW, Wang YP, Lu TY, Wu HC, Liu D, Sun J, Zhu J, Zhou H, Zhang XX, Zhang Y, Wei F, Yang J, Wong DTW, Rabinowits G, Gerçel-Taylor C, Day JM, Taylor DD, Kloecker GH, Brinton LT, Sloane HS, Kester M, Kelly K a., Masyuk AI, Masyuk T V., Larusso NF, Li Q, Shao Y, Zhang XX, Zheng T, Miao M, Qin L, Wang B, Ye G, Xiao B, Guo J, Inal JM, Zheng L, Liu WW, Ren L, Wang XX, Wang TT, Zhang N, Gao Y, Luo H, Navarro-Alvarez N, Tang L, Zhou X, Zhu W, Li H, Wen W, Cheng W, Wang F, Wu YY, Qi L, Fan Y, Chen Y, Ding Y, Xu J, Qian J, Huang ZZ, Wang TT, Zhu D, Shu Y, Liu P, Manuscript A, Im H, Shao H, Park Y Il, Peterson VM, Castro CM, Weissleder R, Lee HH, Kato TT, Mizutani K, Kameyama K, Kawakami K, Fujita Y, Nakane K, Kanimoto Y, Ehara H, Ito H, Seishima M, Deguchi T, Ito M, Jakobsen KR, Paulsen BS, Baek R, Varming K, Sorensen BS, Jørgensen MM, Madhavan B, Yue S, Galli U, Rana S, Gross W, Müller M, Giese N a., Kalthoff H, Becker T, Büchler MW, Zöller M (2014) Clinical significance of CD151 gene expression in non-small cell lung cancer. PLoS One 5:659-671 . https://doi.org/10.1038/nbt.2886.Label-free

53. Gebretsadik G, Menon MKC (2016) Proteomics and Its Applications in Diagnosis of Auto Immune Diseases. Open J Immunol 6:14-33 . https://doi.org/10.4236/oji.2016.61003

54. Pieper R, Gatlin CL, Makusky AJ, Russo PS, Schatz CR, Miller SS, Su Q, McGrath AM, Estock MA, Parmar PP, Zhao M, Huang ST, Zhou J, Wang F, Esquer-Blasco R, Anderson NL, Taylor J, Steiner S (2003) The human serum proteome: Display of 
nearly 3700 chromatographically separated protein spots on two-dimensional electrophoresis gels and identification of 325 distinct proteins. Proteomics 3:13451364 . https://doi.org/10.1002/pmic.200300449

55. Tekin IO, Pocan B, Borazan A, Ucar E, Kuvandik G, Ilikhan S, Demircan N, Ozer C, Kadayifci S (2008) Positive correlation of CRP and fibrinogen levels as cardiovascular risk factors in early stage of continuous ambulatory peritoneal dialysis patients. Ren Fail 30:219-225 . https://doi.org/10.1080/08860220701813350

56. Eva C, Satyanarayana UCR, Denis M, Melanie K, Fabienne DL, Rodolfo LP, Yves C, Christina P, Youssef D, Marc A (2018) Therapeutic drug monitoring of busulfan for the management of pediatric patients: Cross-validation of methods and long-term performance. Ther Drug Monit 40:84-92 . https://doi.org/10.1097/FTD.0000000000000468

57. Shi X, Gao H, Li Z, Li J, Liu Y, Li L, Zhang Q (2019) Modified enzyme multiplied immunoassay technique of methotrexate assay to improve sensitivity and reduce cost. BMC Pharmacol Toxicol 20:1-7 . https://doi.org/10.1186/s40360-018-0283-5

58. Vaught JB, Henderson MK (2011) Biological sample collection, processing, storage and information management. IARC Sci. Publ. 23-42

59. Thavasu PW, Longhurst S, Joel SP, Slevin ML, Balkwill FR (1992) Measuring cytokine levels in blood. Importance of anticoagulants, processing, and storage conditions. J Immunol Methods 153:115-124 . https://doi.org/10.1016/00221759(92)90313-i

60. Adkins JN, Varnum SM, Auberry KJ, Moore RJ, Angell NH, Smith RD, Springer DL, Pounds JG (2002) Toward a Human Blood Serum Proteome. Mol Cell Proteomics 1:947-955 . https://doi.org/10.1074/mcp.M200066-MCP200

61. Nyuwi KT, Gyan Singh CH, Khumukcham S, Rangaswamy R, Ezung YS, Chittvolu 
SR, Barindra Sharma A, Manihar Singh H (2017) The role of serum fibrinogen level in the diagnosis of acute appendicitis. J Clin Diagnostic Res 11:PC13-PC15 . https://doi.org/10.7860/JCDR/2017/21479.9319

62. Chitsaz A, Mousavi SA, Yousef Y, Mostafa V (2012) Comparison of changes in serum fibrinogen level in primary intracranial hemorrhage (ICH) and ischemic stroke. ARYA Atheroscler 7:142-145

63. Goicoechea M, de Vinuesa SG, Gómez-Campderá F, Aragoncillo I, Verdalles U, Mosse A, Luño J (2008) Serum fibrinogen levels are an independent predictor of mortality in patients with chronic kidney disease (CKD) stages 3 and 4. Kidney Int Suppl 68:S67-S70 . https://doi.org/10.1038/ki.2008.519

64. Sheng L, Luo M, Sun X, Lin N, Mao W, Su D (2013) Serum fibrinogen is an independent prognostic factor in operable nonsmall cell lung cancer. Int J Cancer 133:2720-2725 . https://doi.org/10.1002/ijc.28284

65. Yang S-H, Du Y, Zhang Y, Li X-L, Li S, Xu R-X, Zhu C-G, Guo Y-L, Wu N-Q, Qing P, Gao Y, Cui C-J, Dong Q, Sun J, Li J-J (2017) Serum fibrinogen and cardiovascular events in Chinese patients with type 2 diabetes and stable coronary artery disease: a prospective observational study. BMJ Open 7:e015041 . https://doi.org/10.1136/bmjopen-2016-015041

66. Yu X, Hu F, Yao Q, Li C, Zhang H, Xue Y (2016) Serum fibrinogen levels are positively correlated with advanced tumor stage and poor survival in patients with gastric cancer undergoing gastrectomy : a large cohort retrospective study. BMC Cancer 1-12 . https://doi.org/10.1186/s12885-016-2510-z

67. Bonnier F, Baker MJ, Byrne HJ (2014) Vibrational spectroscopic analysis of body fluids: avoiding molecular contamination using centrifugal filtration. Anal Methods 6:5155 . https://doi.org/10.1039/c4ay00891j 
68. Bonnier F, Petitjean F, Baker MJ, Byrne HJ (2014) Improved protocols for vibrational spectroscopic analysis of body fluids. J Biophotonics 7:167-179 .

https://doi.org/10.1002/jbio.201300130

69. Parachalil DR, Bruno C, Bonnier F, Blasco H, Chourpa I, McIntyre J, Byrne HJ (2019) Raman spectroscopic screening of high and low molecular weight fractions of human serum. Analyst 144:4295-4311 . https://doi.org/10.1039/c9an00599d

70. Bonifacio A, Dalla Marta S, Spizzo R, Cervo S, Steffan A, Colombatti A, Sergo V (2014) Surface-enhanced Raman spectroscopy of blood plasma and serum using Ag and Au nanoparticles: A systematic study. Anal Bioanal Chem 406: . https://doi.org/10.1007/s00216-014-7622-1

71. Sacré P, Bleye C De, Chavez P, Netchacovitch L, Hubert P, Ziemons E (2014) Journal of Pharmaceutical and Biomedical Analysis Data processing of vibrational chemical imaging for pharmaceutical applications. J Pharm Biomed Anal 101:123-140 . https://doi.org/10.1016/j.jpba.2014.04.012

72. Li S, Dai L (2011) An improved algorithm to remove cosmic spikes in Raman spectra for online monitoring. Appl Spectrosc 65:1300-1306 . https://doi.org/10.1366/1006169

73. Zhang L, Henson MJ (2007) A practical algorithm to remove cosmic spikes in Raman imaging data for pharmaceutical applications. Appl Spectrosc 61:1015-1020 . https://doi.org/10.1366/000370207781745847

74. Tian Y, Burch KS (2016) Automatic Spike Removal Algorithm for Raman Spectra. Appl Spectrosc 70:1861-1871 . https://doi.org/10.1177/0003702816671065

75. Zhang X, Chen S, Ling Z, Zhou X, Ding DY, Kim YS, Xu F (2017) Method for Removing Spectral Contaminants to Improve Analysis of Raman Imaging Data. Sci Rep 7:1-10 . https://doi.org/10.1038/srep39891 
76. Mozharov S, Nordon A, Littlejohn D, Marquardt B (2012) Automated cosmic spike filter optimized for process Raman spectroscopy. Appl Spectrosc 66:1326-1333 . https://doi.org/10.1366/12-06660

77. Steinier J, Termonia Y, Deltour J (1972) Smoothing and differentiation of data by simplified least square procedure. Anal Chem 44:1906-1909 . https://doi.org/10.1021/ac60319a045

78. Eilers PHC (2004) Parametric Time Warping. Anal Chem 76:404-411 . https://doi.org/10.1021/ac034800e

79. Rooi JJ De, Eilers PHC (2012) Chemometrics and Intelligent Laboratory Systems Mixture models for baseline estimation. Chemom Intell Lab Syst 117:56-60 . https://doi.org/10.1016/j.chemolab.2011.11.001

80. Lieber CA, Mahadevan-Jansen A (2003) Automated Method for Subtraction of Fluorescence from Biological Raman Spectra. Appl Spectrosc 57:1363-1367 . https://doi.org/10.1366/000370203322554518

81. Mahadevan-Jansen A, Richards-Kortum RR (1996) Raman spectroscopy for the detection of cancers and precancers. J Biomed Opt 1:31-70 . https://doi.org/10.1117/12.227815

82. Mahadevan-Jansen A, Lieber CA (2003) Automated Method for Subtraction of Fluorescence from Biological Raman Spectra. Appl Spectrosc Vol 57, Issue 11, pp 1363-1367 57:1363-1367

83. Sahu A, Sawant S, Mamgain H, Krishna CM (2013) Raman spectroscopy of serum: An exploratory study for detection of oral cancers. Analyst 138:4161-4174 . https://doi.org/10.1039/c3an00308f

84. Mehta K, Atak A, Sahu A, Srivastava S, Murali Krishna C (2018) An early investigative serum Raman spectroscopy study of meningioma. Analyst 143:1916- 
1923 . https://doi.org/10.1039/c8an00224j

85. Cássia R De, Borges F, Navarro RS, Giana HE, Tavares FG, Fernandes AB, Junior LS (2015) Detecting alterations of glucose and lipid components in human serum by nearinfrared Raman spectroscopy. Res Biomed Eng 31:160-168 . https://doi.org/10.1590/2446-4740.0593

86. Koo TW, Berger AJ, Itzkan I, Horowitz G, Feld MS (1999) Reagentless blood analysis by near-infrared Raman spectroscopy. Diabetes Technol Ther 1:153-157 . https://doi.org/10.1089/152091599317369

87. Kerr LT, Hennelly BM (2016) A multivariate statistical investigation of background subtraction algorithms for Raman spectra of cytology samples recorded on glass slides. Chemom Intell Lab Syst 158:61-68 . https://doi.org/10.1016/j.chemolab.2016.08.012

88. Kohler A, Kirschner C, Oust A, Martens H (2005) Extended multiplicative signal correction as a tool for separation and characterization of physical and chemical information in Fourier transform infrared microscopy images of cryo-sections of beef loin. Appl Spectrosc 59:707-716 . https://doi.org/10.1366/0003702054280649

89. Liland KH, Kohler A, Afseth NK (2016) Model-based pre-processing in Raman spectroscopy of biological samples. J Raman Spectrosc 47:643-650 . https://doi.org/10.1002/jrs.4886

90. Wold S, Sjöström M, Eriksson L (2001) PLS-regression: A basic tool of chemometrics. Chemom Intell Lab Syst 58:109-130 . https://doi.org/10.1016/S01697439(01)00155-1

91. Afseth NK, Segtnan VH, Wold JP (2006) Raman spectra of biological samples: A study of preprocessing methods. Appl Spectrosc 60:1358-1367 . https://doi.org/10.1366/000370206779321454

92. Carrascal LM, Galván I, Gordo O (2009) Partial least squares regression as an 
alternative to current regression methods used in ecology. Oikos 118:681-690 . https://doi.org/10.1111/j.1600-0706.2008.16881.x

93. Bonnier F, Blasco H, Wasselet C, Brachet G, Respaud R, Carvalho LFCS, Bertrand D, Baker MJ, Byrne HJ, Chourpa I (2017) Ultra-filtration of human serum for improved quantitative analysis of low molecular weight biomarkers using ATR-IR spectroscopy. Analyst 142:1285-1298 . https://doi.org/10.1039/c6an01888b

94. Davis DG, Schaefer DMW, Hinchcliff KW, Wellman ML, Willet VE, Fletcher JM (2005) Measurement of serum IgG in foals by radial immunodiffusion and automated turbidimetric immunoassay. J Vet Intern Med 19:93-96 . https://doi.org/10.1892/08916640(2005)19<93:MOSIIF>2.0.CO;2

95. Ferris RA, Mccue PM, Act D (2009) How to Use a Quantitative Turbidimetric Immunoassay Assay to Determine Immunoglobulin G Concentrations in Neonatal Foals. AAEP Proc 55:45-47

96. Lubran MM (1978) The measurement of total serum proteins by the biuret method. Ann Clin Lab Sci 8:106-110

97. Okutucu B, Dinçer A, Habib Ö, Zihnioglu F (2007) Comparison of five methods for determination of total plasma protein concentration. J Biochem Biophys Methods 70:709-711 . https://doi.org/10.1016/j.jbbm.2007.05.009

98. Uchida Y, Okuzumi Y, Fujishiro M, Kawamura K, Shibasaki M, Shimetani N, Suzuki K (2006) Controversies in the determination of serum albumin concentration in chronic liver diseases. Rinsho Byori 54:1008-1012

99. Supak Smolcic V, Bilic-Zulle L, Fisic E (2011) Validation of methods performance for routine biochemistry analytes at Cobas 6000 analyzer series module c501. Biochem Medica 182-190 . https://doi.org/10.11613/bm.2011.028

100. Luque-Garcia JL, Neubert TA (2007) Sample preparation for serum/plasma profiling 
and biomarker identification by mass spectrometry. J Chromatogr A 1153:259-276 . https://doi.org/10.1016/j.chroma.2006.11.054

101. Parachalil DR, Commerford D, Bonnier F, Chourpa I, McIntyre J, Byrne HJ (2019) Raman spectroscopy as a potential tool for label free therapeutic drug monitoring in human serum: The case of busulfan and methotrexate. Analyst 144:5207-5214 . https://doi.org/10.1039/c9an00801b

102. Hidi IJ, Mühlig A, Jahn M, Liebold F, Cialla D, Weber K, Popp J (2014) LOC-SERS: Towards point-of-care diagnostic of methotrexate. Anal Methods 6:3943-3947 . https://doi.org/10.1039/c3ay42240b

103. Jaworska A, Fornasaro S, Sergo V, Bonifacio A (2016) Potential of Surface Enhanced Raman Spectroscopy (SERS) in Therapeutic Drug Monitoring (TDM). A critical review. Biosensors 6:E17

104. National award for cancer diagnosis spinout company | University of Strathclyde. https://www.strath.ac.uk/whystrathclyde/news/nationalawardforcancerdiagnosisspinou tcompany/. Accessed 7 Dec 2019

105. Wood B New device that can rapidly diagnose disease could save lives - Science. https://www.prnewswire.com/news-releases/new-device-that-can-rapidly-diagnosedisease-could-save-lives-300781671.html. Accessed 7 Dec 2019

106. Hands JR, Dorling KM, Abel P, Ashton KM, Brodbelt A, Davis C, Dawson T, Jenkinson MD, Lea RW, Walker C, Baker MJ (2014) Attenuated Total Reflection Fourier Transform Infrared (ATR-FTIR) spectral discrimination of brain tumour severity from serum samples. J Biophotonics 7:189-199 . https://doi.org/10.1002/jbio.201300149

107. Zhang K, Song C, Li Q, Li Y, Sun Y, Yang K, Jin B (2010) The establishment of a highly sensitive ELISA for detecting bovine serum albumin (BSA) based on a specific 
pair of monoclonal antibodies (mAb) and its application in vaccine quality control. Hum Vaccin 6:652-658 . https://doi.org/10.4161/hv.6.8.11935

108. Cattaneo C, Gelsthorpe K, Phillips P, Sokol RJ (1992) Detection of blood proteins in ancient human bone using ELISA: A comparative study of the survival of IgG and albumin. Int J Osteoarchaeol 2:103-107 . https://doi.org/10.1002/oa.1390020202

109. Miesbach W, Schenk J, Alesci S, Lindhoff-Last E (2010) Comparison of the fibrinogen Clauss assay and the fibrinogen PT derived method in patients with dysfibrinogenemia. Thromb Res 126:e428-e433 . https://doi.org/10.1016/j.thromres.2010.09.004

110. Lin PH, Yeh SK, Huang WC, Chen HY, Chen CH, Sheu JR, Lin CT, Huang YK (2015) Research performance of biomarkers from biofluids in periodontal disease publications. J Dent Sci 10:61-67 . https://doi.org/10.1016/j.jds.2013.06.007

111. Huang Z, McWilliams A, Lui H, McLean DI, Lam S, Zeng H (2003) Near-infrared Raman spectroscopy for optical diagnosis of lung cancer. Int J Cancer 107:1047-1052 . https://doi.org/10.1002/ijc.11500 